\title{
A rare cause of seizure masquerading as neoplasm
}

\author{
Brett Krummert, ${ }^{1}$ Kurt Scherer, ${ }^{2}$ Jennifer Whitley, ${ }^{3}$ Abdelazim Sirelkhatim, ${ }^{4}$ Mukta Panda ${ }^{4}$ \\ ${ }^{1}$ Department of Internal Medicine, University of Tennessee College of Medicine Chattanooga, Chattanooga, Tennessee, USA \\ ${ }^{2}$ Department of Transitional Year, University of Tennessee College of Medicine Chattanooga, Chattanooga, Tennessee, USA \\ ${ }^{3}$ Department of Hospital Medicine, Erlanger Health System, Chattanooga, Tennessee, USA \\ ${ }^{4}$ Department of Neurology, Erlanger Health System, Chattanooga, Tennessee, USA
}

Correspondence to Jennifer Whitley, jennifer.whitley@erlanger.org

\section{Summary}

The authors report the case of a young man with no significant medical history who presented with new-onset seizure and mass-like lesions isolated to the left cerebral hemisphere relating to malignancy. Biopsy revealed findings consistent with angiitis and investigations for secondary causes of angiitis was negative. The diagnosis of primary angiitis of the central nervous system was made and the patient has responded well to treatment.

\section{BACKGROUND}

Primary angiitis of the central nervous system (PACNS) is a rare disorder characterised by granulomatous inflammation of cerebral arteries and arterioles. The vasculitis is limited to the central nervous system (CNS) with no systemic involvement and no secondary causes. The aetiology is unclear and presentation is variable. Prompt recognition and treatment of PACNS is essential as the diagnosis is uniformly fatal if left untreated.

\section{CASE PRESENTATION}

A 44-year-old Caucasian man presented to the emergency department with new onset seizure. The patient awoke the morning of presentation with a headache and right-sided weakness and numbness. He ignored these symptoms and proceeded to work where co-workers witnessed two tonicclonic seizures. He was post-ictal when emergency medical services arrived. His medical history was significant only for alcohol abuse and he was on no medications. He had no significant family history. His initial physical examination revealed a well-developed man in no acute distress and mildly confused. Neurological exam revealed right-sided weakness, paresthesia and pronator drift. His vital signs were stable and the remainder of his physical exam was unremarkable. CT of the brain revealed multiple lesions in the left hemisphere relating to neoplasm either primary or metastatic. MRI revealed multiple enhancing lesions in the left frontal and parietal lobes (figure 1). The largest lesion was $11 \mathrm{~mm} \times 26 \mathrm{~mm} \times 19 \mathrm{~mm}$ and involved the corpus callosum. There were 14 lesions, all of which demonstrated regional oedema and mild mass effect. MR angiogram of the brain demonstrated normal anatomical variants but no arterial occlusion or stenosis. The differential at that time included multicentric glioblastoma multiform, lymphoma, metastatic disease or an infectious aetiology. CT imaging of the thorax, abdomen and pelvis revealed no primary source of metastatic disease.

\section{INVESTIGATIONS}

Due to the concern for malignancy, craniotomy was performed to obtain a biopsy specimen. It was noted at the time of biopsy that the lesions seen on MRI were not tumourous masses but rather areas of necrosis, haemorrhage and inflammation. Histopathology revealed widespread involvement of the cerebral arterioles by a mixed lymphocytic, mildly plasmacytic, vasculitis with focal areas of necrosis of the vessel walls (figure 2). There was associated thrombosis with accompanying areas of ischaemic necrosis. There was no evidence of malignancy or infection. These findings were consistent with lymphocytic vasculits.

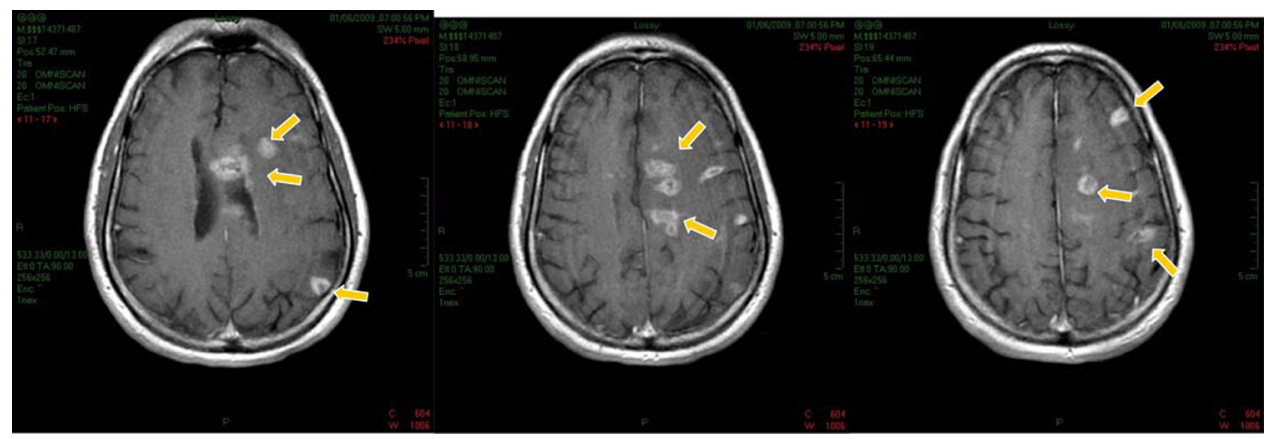

Figure $1 \mathrm{MRI}$ of the brain revealed multiple enhancing lesions in the left frontal and parietal lobes. 


\section{BMJ Case Reports}

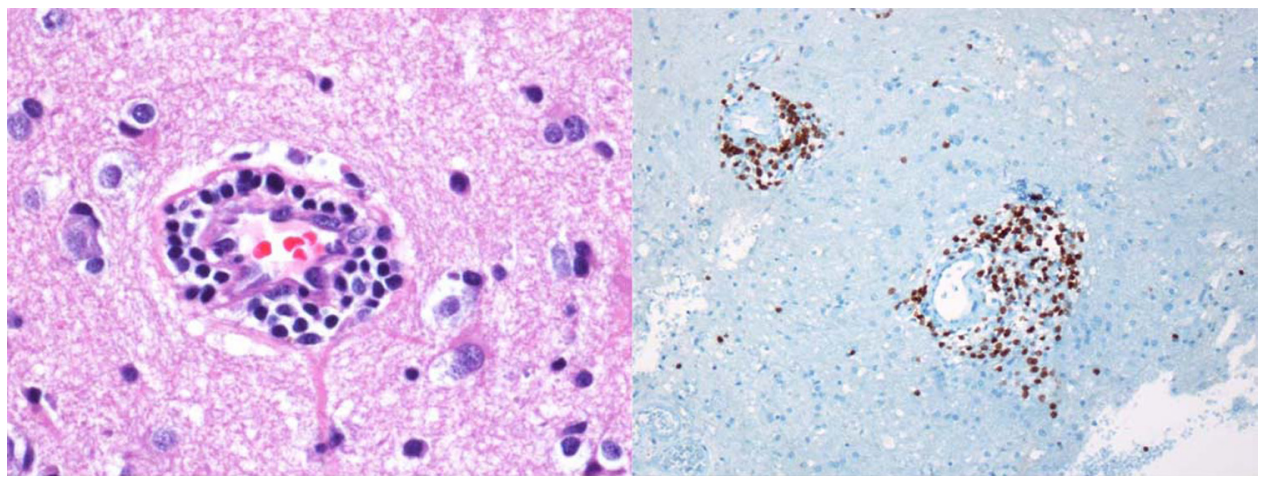

Figure 2 Histopathology revealed findings consistent with lymphocytic vasculitis.

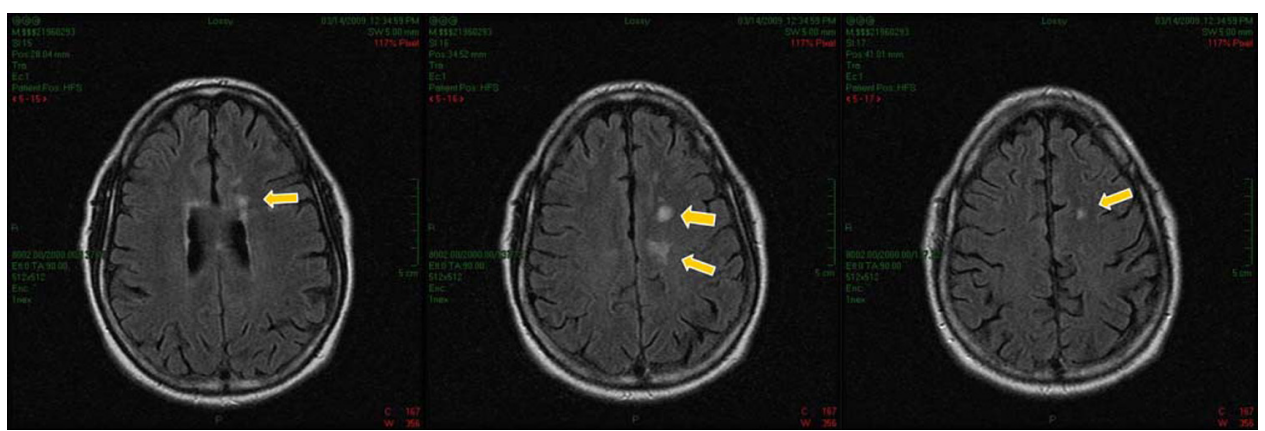

Figure $3 \mathrm{MRI}$ of the brain at 3-month follow-up shows a significant reduction in the size and number of lesions.

Immunohistochemistry showed the lymphocytes to be CD3 positive and CD20 negative. Stains for microorganisms were all normal.

Once the diagnosis of vasculitis was made, an evaluation for secondary causes of vasculitis was pursued. Evaluation included a lumbar puncture, which was significant for lymphocytic pleocytosis, all other cerebrospinal fluid studies were normal. Extensive infectious and rheumatologic investigations were negative for any systemic diseases or secondary causes of vasculitis. The diagnosis of PACNS was made.

\section{TREATMENT}

The patient was started on prednisone and cyclophosphamide. The patient was discharged home with close follow-up.

\section{OUTCOME AND FOLLOW-UP}

After 3 months of treatment, repeat imaging was performed to assess his response (figure 3 ). The neuroimaging revealed an excellent response to treatment with an interval reduction in the size and number of lesions. Over the past year the patient has had no recurrent seizure activity and has tolerated treatment well.

\section{DISCUSSION}

PACNS is a rare disorder that can present with virtually any neurological sign and has variable findings on neuroimaging. ${ }^{1}$ The inconsistent presentation often makes the diagnosis elusive. By definition, the vasculitis is isolated to the CNS. ${ }^{2}$ Secondary causes of vasculiitis must be excluded with a thorough clinical and laboratory evaulation. ${ }^{3}$ This disorder was initially termed Isolated Central Nervous System Vasculitis in the 1950s. Since that time, the aetiology of the disorder has not been clearly elucidated. A viral aetiology has been suggested but the diagnosis is still one of exclusion. ${ }^{45} 6$

Making the diagnosis in a timely manner is crucial because this disorder is invariably fatal if left untreated. ${ }^{7}$ MRI and CT scans are often helpful in the initial investigation, but further evaluation is needed to make a diagnosis. Neuroimaging in PACNS can often mimic other disease processes such as neoplasm, intracranial haemorrhage and demyelinating disorders. ${ }^{8}$ There have even been several case reports of patients with normal neuroimaging. ${ }^{9}$ Angiography is the imaging modality of choice. However, this modality is still somewhat limited because the disease affects the small and medium sized vessels and may not be well visualised. ${ }^{2}$ The gold standard to diagnose PACNS is histopathology. ${ }^{10}$

The histopathology of CNS angiitis has been welldescribed. The inflammation associated with the disease is granulomatous in nature. Macrophages, lymphocytes and multinucleated giant cells are often found in the affected arteries and arterioles. In several case studies, the pathological findings are similar to those found in patients with Takayasu arteritis and giant cell arteritis. ${ }^{10}$ Ischaemia and/or infarction appear to be common in affected patients. While the majority of cases appear to affect the cerebral cortex more than the subcortical regions, our patient's lesions involved the subcortical vessels as well. H\&E sections demonstrate widespread involvement of the cerebral arterioles by a mixed lymphocytic, mildly plasmacytic, vasculitis 
with focal necrosis of vessel walls and thrombosis with accompanying areas of ischaemic necrosis.

Treatment of this disease has significantly improved over the past 50 years. When the disorder was first described in the 1950s it was uniformly fatal. ${ }^{8}$ It was not until several years later that the combination of cyclophosphamide and steroids yielded effective treatment results. Since the introduction of the two-drug regimen, most patients have responded well to treatment. The treatment duration ranges between 6 months and 1 year depending on clinical response. Close follow-up and serial neuroimaging is required to assess response to treatment.

\section{Conclusion}

While PACNS has been recognised since the 1950s, its variable presentation has confounded clinicians and radiologists for decades. The clinician must have a high clinical suspicion for this disease when a patient presents with neurological manifestations not explained by another disease process. MRI and CT scans can aid in developing a differential diagnosis, but neuroimaging should include angiography. Biopsy is often essential in making the diagnosis. Before a diagnosis of PACNS can be made, an exhaustive search should be undertaken to rule out other treatable causes of the vasculitis. Treatment should be initiated as soon as possible. Most patients tolerate treatment well and experience full recovery. Unfortunately, in many patients the diagnosis of PACNS is made postmortem. Hospital team members often encounter new-onset seizure and CNS lesions. It is important for us to keep a broad differential and aggressively pursue definitive diagnosis.

\section{Learning points}

- CNS angiitis is a diagnosis of exclusion.

- Biopsy is often necessary for definitive diagnosis.

- CNS angiitis is treatable if diagnosed early but fatal if left untreated.

- Monitor patients closely for side effects of immunosuppressive treatment.

Competing interests None.

Patient consent Obtained.

\section{REFERENCES}

1. Molloy ES, Singhal AB, Calabrese LH. Tumor-like mass lesion: an underrecognized presentation of primary angiitis of the central nervous system. Ann Rheum Dis 2008;67:1732-5

2. Calabrese LH, Furlan AJ, Gragg LA, et al. Primary angiitis of the central nervous system: diagnostic criteria and clinical approach. Cleve Clin J Med 1992;59:293-306.

3. Calabrese LH, Mallek JA. Primary angiitis of the central nervous system. Report of 8 new cases, review of the literature, and proposal for diagnostic criteria. Medicine (Baltimore) 1988;67:20-39.

4. Alexander JJ, Lasky AS, Graf WD. Stroke associated with central nervous system vasculitis after West Nile virus infection. J Child Neurol 2006:21:623-5.

5. Outteryck $\mathbf{0}$, Sénéchal 0 , Berteloot $\mathrm{D}$, et al. Cerebral vasculitis secondary to Varicella-Zoster virus infection. Rev Neurol (Paris) 2005;161:836-9.

6. Bhat G, Mathur DS, Saxena GN, et al. Granulomatous angiitis of the central nervous system associated with herpes zoster. J Assoc Physicians India 2002:50:977-8.

7. Koo EH, Massey EW. Granulomatous angiitis of the central nervous system: protean manifestations and response to treatment. J Neurol Neurosurg Psychiatr 1988:51:1126-33.

8. Panchal NJ, Niku S, Imbesi SG. Lymphocytic vasculitis mimicking aggressive multifocal cerebral neoplasm: MR imaging and MR spectroscopic appearance. AJNR Am J Neuroradiol 2005:26:642-5.

9. Imbesi SG. Diffuse cerebral vasculitis with normal results on brain MR imaging. AJR Am J Roentgenol 1999;173:1494-6.

10. Parisi JE, Moore PM. The role of biopsy in vasculitis of the central nervous system. Semin Neurol 1994;14:341-8.

This pdf has been created automatically from the final edited text and images.

Copyright 2010 BMJ Publishing Group. All rights reserved. For permission to reuse any of this content visit

http://group.bmj.com/group/rights-licensing/permissions.

BMJ Case Report Fellows may re-use this article for personal use and teaching without any further permission.

Please cite this article as follows (you will need to access the article online to obtain the date of publication).

Krummert B, Scherer K, Whitley J, Sirelkhatim A, Panda M. A rare cause of seizure masquerading as neoplasm. BMJ Case Reports 2010;

10.1136/bcr.07.2010.3133, date of publication

Become a Fellow of BMJ Case Reports today and you can:

- Submit as many cases as you like

Enjoy fast sympathetic peer review and rapid publication of accepted articles

- Access all the published articles

- Re-use any of the published material for personal use and teaching without further permission

For information on Institutional Fellowships contact consortiasales@bmjgroup.com

Visit casereports.bmj.com for more articles like this and to become a Fellow 